\title{
A capital federal nos altiplanos de Goiás - medicina, geografia e política nas comissões de estudos e localização das décadas de 1940 e 1950
}

The federal capital in the plateaus of Goiás: medicine geography, and politics in the research and location commissions of the 1940s and 1950s

Tamara Rangel e Nísia Trindade Lima

De costas para o país, alheio à realidade do interior,

o Governo Federal, constantemente ocupado ou preocupado com os problemas municipais de uma cidade absorvente e impressionante como o Rio, não é, objetivamente,

\footnotetext{
As autoras agradecem ao pesquisador Sérgio Nunes Pereira a indicação de importantes fontes utilizadas neste trabalho.

Tamara Rangel é doutoranda do Programa de Pós-Graduação em História das Ciências e da Saúde da Casa de Oswaldo Cruz/ Fiocruz, Rio de Janeiro, Brasil (tamararangel@yahoo.com.br).

Nísia Trindade Lima é doutora em Sociologia pelo Instituto Universitário de Pesquisas do Rio de Janeiro IUPERJ, pesquisadora da Casa de Oswaldo Cruz/Fiocruz, professora do Programa de Pós-Graduação em História das Ciências e da Saúde e editora científica da Editora Fiocruz, Rio de Janeiro, Brasil (lima@fiocruz.br).

Artigo recebido em 31 de dezembro de 2010 e aprovado para publicação em 24 de fevereiro de 2011.
} 
capaz de atender a este Brasil tão vasto e tão diverso (...). Eis porque, com toda a sinceridade, me convenci de que a mudança da capital não é, atualmente, o maior ou menor problema nacional: é o único Fosé Peixoto da Silveira, membro da Comissão de Localização da Nova Capital Federal

O trecho acima integra o prefácio do livro $A$ nova capital - por que, para onde e como mudar a Capital Federal, organizado pelo médico mineiro e defensor da causa mudancista José Peixoto da Silveira. Com título bastante sugestivo, esta obra reúne uma série de artigos, conferências, entrevistas e capítulos de sua autoria, escritos a partir dos anos 1940, com o objetivo de defender o ponto de vista acima sintetizado. Publicado no momento em que as obras de construção de Brasília caminhavam a todo o vapor e os debates em torno da necessidade e da viabilidade da transferência da capital federal agitavam aqueles que eram favoráveis à ideia e os que se opunham a ela, o livro teria contribuído, segundo palavras de Juscelino Kubistchek no prefácio da segunda edição da publicação, "para esclarecer a opinião pública sobre o sentido da transferência da Capital, dissipando dúvidas e incompreensões" (Silveira, 1997: 148). Das três perguntas a que Peixoto da Silveira se propõe a responder no título de sua obra, uma delas serve de mote a este trabalho - para onde mudar a capital?

O Planalto Central, onde atualmente se encontra o Distrito Federal, foi definido oficialmente como região para onde deveria ser levada a capital do país na Carta Constitucional de 1891. A localização precisa da cidade, no entanto, só foi estabelecida mais de cinquenta anos depois, quando a Comissão de Localização da Nova Capital Federal, organizada pelo governo federal em 1953, chegou a uma conclusão definitiva a respeito do sítio mais adequado para este fim. O processo que se estende da definição da região até a escolha do sítio engloba muitos estudos, efetuados no interior de gabinetes e in loco, realizados por profissionais de diversas áreas do conhecimento e com diferentes pontos de vista sobre a melhor localização da futura sede administrativa do país. Neste artigo, discutimos a importância que argumentos oriundos da medicina e da geopolítica, aliados a interesses regionais, tiveram nas comissões de estudos e de localização organizadas pelos governos de Dutra e Vargas nas décadas de 1940 e 1950, respectivamente.

Brasília tornou-se a meta-síntese da presidência de Juscelino Kubistchek e se este não participara da decisão do local onde deveria ser erguida a nova cidade, transformou-a em um monumento do Brasil moderno que concebeu (Benevides, 1976; Lafer, 2002; Gomes, 2002, Bomeny, 2002; Faro; Silva, 2002). De um modo geral, a historiografia que se ocupou em refletir sobre a nova capi- 
tal toma este projeto como reflexo do espírito empreendedor de JK, de sua grande capacidade de equilibrar os diversos interesses sociais em jogo no pacto político sobre o qual seu governo se apoiava, ou como fruto da convergência desses interesses em torno da política econômica desenvolvimentista abraçada pelo presidente, sintetizada em seu Programa de Metas (Skidmore, 1982; Mendonça, 1985; Moreira, 1998; Benevides, 2002; Faro; Silva, 2002; Lafer, 2002; Leopoldi, 2002).

Alguns trabalhos, no entanto, chamam a atenção para a mobilização dos goianos na fase final desse processo, ressaltando seu importante papel na viabilização da transferência da capital (Silva, 1997; Moreira, 1998; Oliveira, 2005a; 2005b). Atentar para essa participação interessada de Goiás no processo de escolha e efetivação da mudança e reforçar a dimensão regional contida neste projeto é, também, um de nossos objetivos.

O peso dos argumentos geopolíticos sobre a definição dos altiplanos de Goiás como região mais adequada para a capital também não costuma ser enfatizado nos trabalhos que se dedicam a uma reflexão sobre a construção de Brasília. Do mesmo modo, não é considerada a recorrente preocupação com a salubridade local manifestada pelos integrantes das diferentes comissões organizadas desde o final do século XIX, com o fim de analisar o Planalto Central. Uma das exceções à regra pode ser percebida na recente publicação Veredas de Brasília - as expedições geográficas em busca de um sonho. Iniciativa do IBGE em homenagem aos 50 anos da capital federal, o livro possui como objetivo central enfatizar a participação do órgão na trajetória de Brasília. Desta obra, destacamos o capítulo escrito por Sérgio N. Pereira (2010), que versa sobre a Comissão de Estudos para Localização da Nova Capital do Brasil, empossada em 1946, no governo Dutra.

Com uma abordagem que se afina com as pretensões inicialmente esboçadas neste artigo, Pereira ressalta a participação de geógrafos, estatísticos e militares nos debates travados tanto no seio da própria comissão quanto em espaços institucionais a ela relacionados, como o Conselho Nacional de Geografia e o Serviço Geográfico do Exército, este último representado pelo chefe da comissão. O peso dos argumentos geográficos nas conclusões a que chegaram os membros desta comissão em 1948 a respeito da melhor localização para a capital é enfatizado pelo autor, que se preocupa em localizar historicamente os pontos de vista de alguns deles no âmbito maior do pensamento geopolítico, ressaltando as linhas teóricas e os autores com as quais dialogavam. O reflexo disso está na polarização da decisão final entre aqueles que optaram pelo Triângulo Mineiro e aqueles que preferiram a área definida pela Comissão Cruls, no relatório publicado em 1894.

Considerado tema clássico da imaginação espacial brasileira (Maia, 2010), e um dos mais debatidos no período por nós trabalhado, a mudança da ca- 
pital não foi apenas um dos tópicos na agenda de preocupações daqueles interessados em refletir sobre a geopolítica nacional. A ideia de fixar a capital federal no Brasil Central nos anos 1940 coadunou-se com a política de integração do território pátrio levada a cabo durante o governo de Vargas, no qual a geopolítica ocupava posição de destaque (Moraes, 2005). Iniciativas como a Fundação Brasil Central e as Colônias Agrícolas Nacionais visavam à exploração da parte ainda pouco conhecida do território, bem como sua ocupação e integração. A Marcha para o Oeste, tão propagada pelos intelectuais deste período, refletia, pois, essa preocupação com a existência de enormes “espaços vazios" sobre os quais o Estado deveria manter sua soberania, no que a política governista e o ideário geopolítico se aproximavam (Miyamoto, 1992). Neste sentido, pode-se afirmar que a construção de Brasília nos anos 1950 reflete, de certo modo, esse Estado territorialista e expansionista da década anterior.

Em suma, partindo do interesse nessas questões, propomos, com este trabalho, mostrar de que forma argumentos provenientes da medicina e da geopolítica apareceram associados aos interesses políticos goianos no bojo das atividades desenvolvidas pelas comissões organizadas nas décadas de 1940 e 1950 . Acreditamos estar contribuindo, assim, para um entendimento mais amplo e complexo sobre as implicações contidas nas decisões das duas comissões aqui analisadas, proporcionando um olhar mais atento para a história da ideia mudancista.

\section{A primeira das comissões: Comissão Cruls}

A resposta à pergunta "para onde" levar a capital começou a ser esboçada no final do século XIX, quando ficou definido na Constituição republicana de 1891 que a futura capital federal deveria ser estabelecida no Planalto Central. No entanto, os autores que se dedicam a traçar um histórico da ideia mudancista identificam menções ao desejo de mudança e interiorização da capital do Brasil pelo menos um século antes (Cf. Varnhagen, 1877; Couto, 2001; Cruls, 2003; Ceballos, 2005; Kubitschek, 2006). Entre os personagens mais citados como precursores dessa ideia estão Francisco Tosi Colombina, que teria viajado ao interior do Brasil e deixado mapas e escritos a respeito no século XVIII, Hipólito José da Costa, que através de seu jornal Correio Braziliense defendia a necessidade de a Corte se dirigir para um ponto central do país (tal como fazia José Bonifácio de Andrada na Assembleia Constituinte e Legislativa do Brasil), e Francisco Varnhagen, um dos últimos a se preocupar com a questão, antes de sua inclusão na Carta constitucional de 1891. 
Durante o governo de Floriano Peixoto, mais precisamente em 1892, foi organizada aquela que talvez seja a mais conhecida comissão de estudos criada com o fim de estudar e demarcar, no Planalto Central, a região para onde deveria ser levada a capital do país: a Comissão Exploradora do Planalto Central do Brasil ou Comissão Cruls (Rosas, 1996; Vergara, 2006, 2008 e 2010). Através de seu relatório, publicado em 1894, concluiu-se que o espaço percorrido pelos 22 membros da comissão (entre militares, médicos, botânicos, geólogos, astrônomos e farmacêuticos) possuía as maiores qualidades possíveis para abarcar o empreendimento. Além de perfeito em termos de recursos naturais e salubridade, 0 Planalto Central contaria com privilegiada localização. As facilidades de comunicação decorrentes da centralidade deste território intensificariam as relações internas entre os estados e as relações externas entre nações. Além disso, a região não sofreria com os perigos de invasão estrangeira, diferenciando-se da vulnerabilidade atribuída ao litoral, pois, ao contrário deste, o Planalto Central contaria com "pontos estratégicos" de defesa militar. A facilidade de aclimatação do trabalhador europeu à região também aparece no relatório Cruls, ressaltando-se a amenidade do clima e a salubridade, decorrentes das maiores altitudes em relação ao litoral (Cruls, 2003). ${ }^{1}$

Do ponto de vista da higiene, faz-se necessário uma breve contextualização dos argumentos elencados pelo médico da comissão Antônio M. de Azevedo Pimentel, em relatório que já foi objeto de acurada análise por parte de Moema Vergara (2006; 2008). Devemos lembrar, por exemplo, que a ênfase dada ao clima ameno, às maiores altitudes, à baixa umidade e ao calor não excessivo da região se explica pela relação profunda que os médicos e sanitaristas julgavam existir entre tais aspectos e as condições de salubridade no período em questão. Embora outras vertentes explicativas das causas de doenças e problemas sanitários já figurassem no panorama médico-científico da época, os pressupostos do paradigma ambientalista - isto é, que levavam em conta as condições do meio ambiente como a qualidade das águas e do ar na propagação de doenças - ainda se faziam presentes. A própria preocupação em afirmar a amenidade do clima configura um aspecto relevante do período, uma vez que o desejo de o país se inserir no concerto das nações civilizadas era inviabilizado pela associação comumente feita entre o Brasil e os trópicos (Ferreira, 2001). Outro aspecto relevante refere-se à posição estratégica conferida ao Planalto Central: em uma época em que o perigo de invasões estrangeiras se dava por via marítima, melhor seria se a capital não estivesse localizada no litoral.

Apesar de a região palmilhada pela Comissão Cruls ter sido analisada e demarcada, configurando, deste então, um retângulo nos mapas do Brasil, e apesar da ampla divulgação de seus trabalhos, em especial por parte do próprio Azevedo Pimentel (Vergara, 2008; 2010), outras comissões a sucederiam e muitos 
anos se passariam até que o preceito constitucional fosse finalmente concretizado. A importância dada à salubridade do Planalto Central, no entanto, não deixaria de figurar na pauta de preocupações daqueles mais diretamente envolvidos com a questão da transferência da capital e voltaria à tona nas comissões organizadas posteriormente.

\section{O encontro da história com a geografia: os estudos da Comissão Polli Coelho}

Após referências pontuais nas Constituições seguintes (1934 e 1937), a questão da mudança da capital federal só foi retomada de fato nos anos 1940, durante o governo do marechal Eurico Gaspar Dutra. Após acalorados debates sobre o tema na imprensa e na Assembléia Nacional Constituinte, envolvendo personagens como Juscelino Kubitschek, Lucas Lopes, Israel Pinheiro e Pedro Ludovico Teixeira, o Planalto Central ficou mantido na Constituição de 1946 como região privilegiada para os futuros trabalhos demarcatórios, bem como a indicação de que uma comissão de técnicos fosse nomeada para proceder aos respectivos estudos (Couto, 2001; Bojunga, 2001; Silveira, 1957). A Comissão de Estudos para a Localização da Nova Capital foi empossada em novembro de 1946 e deveria levar em consideração o trabalho que havia sido empreendido pela Comissão Cruls, embora não precisasse se restringir aos mesmos. Estava constituída por 12 técnicos, chefiados pelo general Djalma Polli Coelho, os quais deveriam se dividir entre trabalhos de gabinete e de campo. Seus membros eram todos engenheiros, ${ }^{2}$ que se diferenciavam por suas especialidades, com a única exceção do médico-sanitarista Geraldo H. de Paula e Souza.

Desde que foi empossada, no final de 1946, até a conclusão dos trabalhos, em 1948, os membros da comissão se reuniram 23 vezes, segundo podemos depreender das atas de suas sessões (Comissão..., 1948). Uma das primeiras medidas tomadas nestas reuniões foi a organização de seu regimento interno, no qual ficou determinada a criação de subcomissões permanentes e de estudos especiais. As subcomissões permanentes eram de dois tipos: Investigações Geográficas, sob a direção de Christovam Leite de Castro, então secretário-geral do Conselho Nacional de Geografia (ligado ao Instituto Brasileiro de Geografia e Estatística), e a de Investigações Urbanísticas, sob a direção de Luiz de Anhaia Mello. As subcomissões de estudos especiais dedicaram-se aos temas da geologia, agronomia, energia e clima. Com base nos relatórios deixados por esta comissão e em periódicos como Boletim Geográfico e Revista Brasileira de Geografia, nas quais alguns de seus trabalhos foram publicados e artigos sobre o tema eram 
frequentes, é possível identificar os assuntos que mais animavam os debates entre os técnicos.

Entendendo a Comissão que sua função era a de situar, dentro da região do Planalto Central, o território mais adequado para o futuro Distrito Federal, seus membros não se restringiram ao retângulo demarcado anteriormente por Cruls, embora aquela região fosse a preferida de Polli Coelho, então chefe da comissão. ${ }^{3}$ Sob a chefia de Leite de Castro, duas expedições geográficas foram organizadas em 1947 com o objetivo de estudar o Planalto Central e indicar sítios adequados para localização da capital dentro das zonas selecionadas (Guimarães, 1949a; 1949b; Castro, 1948b; Ruellan, 1947).

As conclusões a que estas expedições chegaram, após sete meses de trabalhos de campo, transformaram-se em relatórios que circularam entre os membros da comissão e foram debatidos em suas sessões plenárias. Tomando por base critérios como clima, topografia, abastecimento d'água, proximidade de floresta, energia hidráulica, materiais de construção, natureza do subsolo e paisagem atraente para a análise de sítios, e os critérios de posição em relação às regiões mais povoadas do país e mais desenvolvidas, a zona que incluía o retângulo Cruls ficou em quinto lugar em relação às demais. Embora apresentasse sítios excelentes no que se refere ao clima e à topografia, foi considerada deficiente com relação aos demais tópicos: além de estar muito distante do ecúmeno brasileiro, apresentando uma densidade demográfica muito baixa, seus solos seriam pobres, sua paisagem monótona, seus recursos hídricos parcos e o Vão do Paranã (a nordeste do quadrilátero) seria uma das zonas mais assoladas pela malária no Brasil Central (Guimarães, 1949: 55-57). A zona que abrangia a área de Uberlândia foi indicada como a mais apropriada para sediar a nova capital.

Apesar de tais conclusões, "o Retângulo Cruls iria revelar-se como um baluarte inexpugnável” (Pereira, 2010:61) e os pontos considerados críticos seriam questionados por aqueles que, no seio da comissão, defendiam a solução Cruls como a mais acertada. A localização da capital, por exemplo, se no centro geográfico ou no centro demográfico do país, colocava em questão o conceito de posição adotado pelos geógrafos envolvidos nos trabalhos da comissão. Apesar de concordar com o fim do "ciclo do Rio de Janeiro ou litorâneo", Leite de Castro - então chefe das expedições que haviam estudado in loco o Planalto Central temia pelo isolamento da nova capital, caso ela fosse instalada no centro geométrico do país. Demonstrava, por isso, inclinação favorável à localização da capital em local mais povoado, de onde fosse possível aspirar recursos e projetá-los a favor da parte mais "vazia". Como profissional da área, ressaltava o importante papel da geografia nos trabalhos desenvolvidos pela comissão, destacando o povoamento como aspecto muito relevante (Castro, 1946). 
Considerando os aspectos geográficos como secundários, Polli Coelho defendia sua preferência com argumentos provenientes da geopolítica, atualizando velhas questões e incorporando temas como a fragilidade do sistema federalista. ${ }^{4}$ Ele e os demais membros que compartilhavam do mesmo ponto de vista consideravam de suma importância que a capital fosse levada para a região já delimitada por Cruls, onde "a resistência econômica e militar do Brasil contra qualquer ameaça ou ataque poderia ser maior e melhor organizada" (Coelho, 1948a: 21). Defendia que a capital também teria uma função colonizadora, e pouco importava o fato de a zona ser de baixa densidade demográfica: o mais importante é que ela ficasse numa posição central para influir no desenvolvimento do interior despovoado (Coelho, 1948b). Os demais pontos negativos, relacionados com a pobreza de recursos, ora eram rebatidos com base nos estudos específicos realizados pelos próprios membros da comissão, ora eram reafirmados, já que se tratava de escolher uma região adequada para os serviços burocráticos do Estado e não um lugar propício para a indústria e/ou agricultura (Coelho, 1948b; 1948c). Apesar da prioridade conferida à geopolítica, Polli Coelho não descartava outros aspectos que ajudavam a reforçar as qualidades do Planalto Central goiano (Coelho, 1948b: 14).

A salubridade da região estava entre estes aspectos. No âmbito da comissão, as considerações a respeito deste tema deveriam ficar a cargo do médico que a integrava. No entanto, a participação de Geraldo H. de Paula e Souza ao longo dos trabalhos desenvolvidos pela comissão foi pouco expressiva. Através das atas das sessões, percebemos a baixa frequência do médico, que compareceu a apenas cinco delas, fazendo-se presente pela primeira vez quando a comissão já realizava sua $12^{\mathrm{a}}$ sessão. Sua ausência se justificava, geralmente, pelos compromissos que assumia em viagens para o exterior, como quando de sua participação na $3^{\mathrm{a}}$ sessão da Comissão Interina da Organização Mundial da Saúde, em Genebra, da qual era membro e vice-presidente (Rodrigues, 2008).

A primeira sessão em que Paula e Souza esteve presente aconteceu após um interregno de sete meses, período em que se desenvolveram os trabalhos já mencionados das expedições geográficas. Nesta e nas duas sessões subsequentes, Paula e Souza tomou conhecimento do resultado destes trabalhos e de estudos realizados pelas seções especializadas de agronomia e de energia. Ausente na última sessão do ano de 1947, quando ficou definido que cada um dos membros refletiria individualmente sobre os trabalhos até então realizados e elaborariam pareceres indicando suas escolhas, Paula e Souza compareceu à primeira sessão de 1948, que contou com a totalidade de seus membros. A previsão era de que naquele dia todos apresentassem seus votos, mas a necessidade de uma nova excursão ao Planalto Central - aventada por aqueles que não haviam efetuado estudos de campo, entre eles Paula e Souza - adiou a decisão final. 
Tal excursão foi dirigida pelo engenheiro Jerônimo Coimbra Bueno, figura importante que deve ser destacada neste trabalho. Goiano, formado pela Escola de Engenharia da Universidade do Rio de Janeiro, foi responsável, juntamente com seu irmão, pela construção de Goiânia, cidade inaugurada em 1935. Tendo concorrido e vencido as eleições para o governo de seu estado em 1947, governou até 1950, acumulando as funções de governador e membro da comissão de estudos. Considerado como o "homem que construiu politicamente Brasília" (Silva, 1997:39), alguns autores afirmam que Coimbra Bueno valia-se de seu cargo para fazer propaganda mudancista (Silveira, 1997; Silva, 1997; Moreira, 2000). Seu empenho a favor da transferência da capital para o Planalto Central goiano reflete-se, por exemplo, na inclusão de um dispositivo relativo à causa mudancista na própria Constituição do estado de Goiás, promulgada em julho de 1947. Com esse dispositivo, ficava estabelecido o desmembramento automático da parcela do território goiano que fosse delimitada pelo governo federal para a futura capital (Silveira, 1957: 267).

O processo de votação deveria ser retomado com o retorno dos técnicos dos "altiplanos setentrionais de Goiás". A necessidade, porém, de melhor apreciação dos documentos por parte da maioria fez com que ele fosse adiado por mais um mês.

Em missão do governo na Europa, Paula e Souza encaminhou seu voto por escrito. Assim procedendo, sua justificativa de voto é uma das mais resumidas e menos conclusivas do grupo. Englobando em duas áreas as tendências preferenciais da comissão, a do norte e a do sul, optou por esta última, tendo em vista principalmente outros aspectos que não os sanitários, já que

do ponto de vista higiênico e sanitário, os métodos científicos modernos de um modo geral permitem estabelecer-se a proteção sanitária de uma ou de outra área, já que sob esse aspecto, elas não parecem encerrar diferenças fundamentais a tal ponto que se tenha uma base para optar decisivamente por uma delas (Souza, 1948: 138).

Menciona também o grande número de indivíduos atacados por bócio no norte, mas afirma pela necessidade de análises mais acuradas destes espaços, antes de estabelecer um parecer mais contundente. Ao que tudo indica, ele não concluiu o relatório que estaria preparando sobre as condições sanitárias das regiões em questão (Comissão..., 1948:65).

É possível ter acesso, no entanto, a outros documentos em que a questão da salubridade é abordada. Na justificativa de voto apresentada por Luiz da Silva Vieira, por exemplo, este deveria ser um tema apreciado com prudência, "dado o 
conceito corrente concretizado na expressão dura de ser o nosso país um vasto hospital" (Vieira, 1948: 87). Assegura, no entanto, que a região indicada para o novo Distrito Federal seria uma das "mais salubres do Brasil" (Vieira, 1948: 88). As impressões pessoais de Polli Coelho coadunam-se com a afirmação de Silva Vieira: "Durante minha viagem ao Planalto, tive a preocupação constante de observar as condições de saúde da respectiva população que agora considero uma das mais favorecidas do nosso interior" (Coelho, 1948b: 35). No relatório apresentado pelo agrônomo Arruda Câmara, nota-se que, para além dos aspectos agrológicos, sua atenção também esteve voltada para o modo de vida das populações, suas condições de moradia, vestimenta e alimentação. A salubridade, segundo ele, "favoráveis como são, geralmente, as condições climáticas - será assegurada em qualquer das regiões em estudo" (Coelho, 1948b: 21). Para ele, a presença da malária não impediria o povoamento e algumas medidas de saneamento, tais como desobstrução dos leitos e drenagem das terras alagáveis, seriam suficientes para garanti-lo.

Outro documento interessante foi apresentado por Coimbra Bueno na sessão anterior àquela em que se deu a resolução final. Refere-se a uma inspeção sanitária realizada na Chapada dos Veadeiros e no quadrilátero Cruls por uma comissão de sanitaristas convidada pela Secretaria de Saúde do Estado de Goiás. ${ }^{5}$ Entre suas conclusões, destacam-se as seguintes:

(...) 1. A incidência relativa ao grupo de doenças infecciosas e parasitárias pode ser comparada à de qualquer lugar tido como salubre no Brasil; 2. A malária e a doença de Chagas constituem problemas da região estudada, bem como de grande parte do Brasil, suscetíveis de serem resolvidas; 3 . No que diz respeito ao bócio existente em todo o Planalto Central e fora dele, com sua profilaxia já conhecida e eficaz, como vem sendo feita em quase todos os países civilizados, é de se esperar que o Brasil siga em breve esse exemplo na solução de tal problema (...) (Comissão..., 1948: 75).

Com a leitura desta comunicação às vésperas da votação final, Coimbra Bueno esperava, provavelmente, poder sanar algumas dúvidas existentes quanto à salubridade daquela região e com isso, talvez, angariar votos favoráveis à transferência da capital para aquela parte do Planalto Central.

Em 22 de julho de 1948 chegou-se a uma decisão final. Entre as zonas definidas, os membros da comissão dividiram-se entre duas localidades, que apontavam justamente duas tendências: uma para o centro geométrico, mais próxima do retângulo demarcado por Cruls; e outra para o centro demográfico, no Triân- 
gulo Mineiro. Entendendo que a função primordial da nova capital seria proporcionar ao governo condições excelentes de instalação e proximidade com a parte mais povoada do país, a minoria - que contava entre seus proponentes com Paula e Souza, Leite de Castro e Lucas Lopes -, optou por uma área de $6.000 \mathrm{~km}^{2}$, localizada no Triângulo Mineiro, onde seria possível encontrar vários sítios adequados ao empreendimento, que, por conta de tantas facilidades, poderia ser concretizado imediatamente (Castro, 1948a). Anos mais tarde, Lucas Lopes afirmaria em um depoimento:

(...) havia os que tinham uma visão global, de que o importante era que a capital ficasse não no interior de Goiás, mas num ponto que dominasse politicamente o Brasil Central. Todo o meu interesse em levar a capital para o Triângulo Mineiro foi de caráter político. Eu sentia que a capital no Triângulo Mineiro seria capaz de conquistar o Brasil Central porque aquela região tinha bases econômicas boas e estava ligada ao que eu chamava de core área, a área medular do Brasil econômico. Todo o efeito econômico do Triângulo Mineiro poderia ser projetado sobre a bacia amazônica, o Tocantins, etc. Além disso, era uma área próxima às fronteiras do sul do Brasil, que eram as fronteiras mais tensas (Lopes, 1991: 100).

Já a maioria, que contava com o presidente da comissão e com Coimbra Bueno, optou pelo centro geométrico do Brasil, numa região praticamente despovoada e inexplorada, compreendendo que a nova capital também teria uma função colonizadora, devendo a mudança, no entanto, efetuar-se após a execução de um largo programa. Assim, dentro de uma área de cerca de $78.000 \mathrm{~km}^{2}$ - formada de terras do leste do estado de Goiás, confinando a leste com os estados da Bahia e Minas Gerais, e abrangendo ao sul e parte do oeste o retângulo demarcado pela Comissão Cruls em 1892, e, ao norte, a Chapada dos Veadeiros - deveria ser escolhido o melhor sítio para a nova capital (Castro, 1948a).

No documento final preparado pela comissão Polli Coelho são abordados alguns dos principais temas que movimentaram suas discussões: a relevância do ponto de vista geopolítico na determinação do melhor local para a capital, a existência de recursos naturais e financiamento do empreendimento. A salubridade, neste documento, é considerada juntamente com clima e população, recaindo a ênfase neste último ponto. Com relação à salubridade, não se escondem os problemas: 
(...) Como todas as regiões do interior do Brasil, com uma população abandonada a si mesma na ignorância e na indigência, os atuais habitantes do Território recomendado são vítimas fatais das endemias comuns, como a malária, verminoses, bócio e outras (...) (Coelho, 1948a: 25).

As vantagens de se mudar a capital federal para aquela região residiam justamente na oportunidade de livrar tal "população abandonada" desses males, através do emprego de "processos conhecidos e provados em todo o mundo".

Após receber o relatório, o presidente encaminhou as conclusões a que chegou a comissão ao Congresso Nacional, tal como mandava a Constituição. Uma vez no Congresso, estes estudos foram analisados por uma comissão instituída para tal, que chegou a uma decisão diferente daquela postulada pela comissão Polli Coelho. Reações ao relatório final produzido por esta comissão fizeram com que o projeto ficasse parado. Cinco anos depois, retomadas as conclusões da comissão Polli Coelho, o Poder Executivo deu seguimento ao projeto organizando uma nova comissão (Pereira, 2010:73).

\section{Para onde levar a capital? A definição do sítio exato para Brasília}

Em janeiro de 1953, no governo de Getúlio Vargas, foi votada e sancionada a lei que autorizava o Poder Executivo a realizar os estudos definitivos necessários à localização da nova capital no Planalto Central, e concluí-los no prazo de três anos. No parágrafo primeiro deste artigo, entre as condições que deveriam ser satisfeitas por tais estudos, figuram inicialmente o clima e a salubridade favoráveis, seguidos pela facilidade de abastecimento de água e energia elétrica, facilidade de acesso às vias de transporte terrestres e aéreos, topografia adequada, solo favorável às edificações e existência de materiais de construção; proximidade de terras para cultura e por último, paisagem atraente (Brasil, 1953).

Em junho do mesmo ano, foi nomeada a Comissão de Localização da Nova Capital Federal, sob a presidência do general Aguinaldo Caiado de Castro, chefe da Casa Militar da Presidência da República. Entre seus membros figurava Jerônimo Coimbra Bueno, participante da comissão instituída no governo anterior. ${ }^{6}$ Segundo análise de Castiglione (2010), embora se tratasse de uma comissão composta por vários membros, ela parecia reduzida à figura de seu presidente, tendo em vista que seus trabalhos basicamente se resumiam às suas iniciativas. A opção pela estratégia aerofotogramétrica para levantamento da área a ser estudada, técnica ainda não muito comum no período, mostrar-se-ia fundamental para 
que a construção de Brasília fosse levada a cabo em tão pouco tempo (Castiglione, 2010: 95). Para tanto, foi contratada a empresa estrangeira Donald J. Belcher and Associates Incorporated e de seu trabalho resultou um laudo onde cinco sítios foram sugeridos como mais adequados à construção da nova capital (Silveira, 1957; Castiglione, 2010).

Após o suicídio de Vargas, Café Filho assumiu a presidência e o marechal José Pessoa Cavalcanti de Albuquerque substituiu Caiado de Castro à frente da Comissão. Entre os nomes que passaram a integrá-la estavam os de José Peixoto da Silveira, médico que se destacou como um dos grandes defensores da causa mudancista, e Fábio Macedo Soares Guimarães, geógrafo que havia participado de uma das expedições ao Planalto Central na comissão Polli Coelho. ${ }^{7}$ Após análise cuidadosa do material fornecido pela empresa norte-americana, em 30 de abril de 1955 a comissão definiu o sítio de cor castanho ${ }^{8}$ como o mais adequado (Silveira, 1957; Couto, 2001; Castiglione, 2010). Segundo José Pessoa, em exposição à imprensa em janeiro de 1956, as condições climáticas associadas à salubridade foram norteadoras da escolha:

(...) clima ameno, seco e salubérrimo daquele futuro centro urbano, a cerca de $1.150 \mathrm{~m}$ sobre o nível do mar, que fará da nova capital um lugar ideal para se viver e trabalhar, cercado de belos panoramas e magníficos horizontes (...) (Silveira, 1957: 273-274).

Entre os membros da comissão chefiada por José Pessoa, Peixoto da Silveira talvez tenha sido um dos que mais lutou em prol da causa mudancista. Embora mineiro de nascimento, teve toda sua trajetória profissional em Goiás. Foi contratado como o primeiro médico da Colônia Agrícola Nacional de Ceres em 1941 e aos 40 anos ingressou na carreira política. Atuou em Goiás como prefeito, deputado estadual, secretário de Saúde do estado (por duas vezes), secretário da Fazenda, secretário de Educação e Cultura e finalmente deputado federal. Enquanto se desenrolavam os trabalhos da comissão Polli Coelho, o deputado Peixoto da Silveira engajou-se na defesa da interiorização da capital nas sessões da Assembléia Legislativa do estado. Em uma delas, pediu a seus pares que apresentassem trabalhos de divulgação sobre as vantagens da transferência da capital do país para aquela região. $\mathrm{O}$ bem sucedido exemplo de Goiânia e os benefícios que o empreendimento mudancista traria para Goiás deveriam servir de incentivo para que os deputados ali presentes se empenhassem em dar a conhecer as excelências do Planalto Central (Silveira, 1957:221).

Na posição de secretário da Saúde e Assistência do Estado de Goiás, cargo que exerceu entre 1951 e 1954 no governo de Pedro Ludovico Teixeira, Peixoto da 
Silveira foi entrevistado pelo jornal $O$ Globo em maio de 1953 sobre a questão da transferência da capital. Na ocasião, afirmou que "[c]omo médico, conhecedor da região e Secretário da Saúde do Estado de Goiás, posso assegurar que são excelentes as condições de clima e salubridade do Planalto Central do Brasil (...)" (Silveira, 1957: 202). Complementando o quadro positivo, disse que as condições de salubridade seriam indiscutíveis e Brasília seria mesmo um paraíso:

(...) Completando as indiscutíveis condições de salubridade, há numerosos cursos de água, em abundância, de fácil captação e excelente índice de potabilidade. A própria topografia da região, que não é montanhosa e nem chata, mas suavemente ondulada, além de proporcionar os mais belos panoramas, muito facilitará a arquitetura e as obras públicas de calçamento, água e esgoto. Nestas condições - e debeladas algumas endemias de fácil saneamento, hoje, pelos modernos processos - Brasília será uma nova e verdadeira "Xangri-Lá” (...) (Silveira, 1957: 203).

Muito se debateu sobre a questão mudancista durante todo o período de construção de Brasília e múltiplos argumentos foram mobilizados, tanto por quem reclamava pela necessidade da transferência, quanto por aqueles que eram totalmente contrários à sua efetivação. Quando não se opunham à ideia da mudança, criticavam a forma como o projeto era conduzido ou desqualificavam a região escolhida para abrigar a nova capital, apontando seus vários pontos negativos, entre eles a insalubridade local, a secura do clima e a infertilidade das terras. No livro citado na introdução deste artigo, $A$ nova capital, organizado por Peixoto da Silveira, há uma passagem interessante em que o autor busca amenizar os pontos negativos da região do planalto goiano:

(...) Alegam que o Planalto Central é seco e árido. Afirmam isto, simplesmente, sem levar em conta todos os demorados, repetidos e conclusivos trabalhos de técnicos e cientistas, nacionais e estrangeiros, encarregados dos estudos da região. (...) Os estudos realizados comprovam não somente a abundância de água, como a fertilidade da região, onde os próprios terrenos das proximidades do sítio escolhido para plantar a cidade não são áridos, como poderiam parecer à primeira vista. São terras que, mesmo sem tratamento, comportam várias lavouras, que aliás já existem, rotineiramente, na região. Mas, ainda que aquele local fosse impróprio para a agricultura, o clima e a salubridade exce- 
lentes o tornam muito próprio para a finalidade de se fundar uma capital (Silveira, 1957: 161).

Perguntado, certa vez, sobre os efeitos da publicação do livro acima citado sobre a mudança da capital, Peixoto da Silveira respondeu exaltando o entusiasmo, a coragem e a determinação de Juscelino Kubistchek, características às quais se devia "exclusivamente" a mudança da capital (Silveira, 1997: 148). No entanto, a participação dos goianos na concretização do empreendimento foi de suma importância e, mais uma vez, merece destaque.

Uma vez definida a localidade para assento da capital - que parecia preencher todas as exigências impostas pela legislação, inclusive os de ordem sanitária -, foi necessário que o governador de Goiás, José Ludovico de Almeida, atendesse a um pedido do marechal José Pessoa e baixasse um decreto declarando ser de utilidade pública toda a área do futuro Distrito Federal, o que aconteceu em 30 de abril de 1955. Cinco meses depois, foi criada a Comissão de Cooperação para Mudança da Capital, mais uma iniciativa de peso dos goianos, que contribuiria para tornar possível a concretização da meta-síntese do governo JK, tendo em vista que seu objetivo era efetuar a desapropriação por baixos preços de grandes áreas do futuro Distrito Federal (Castiglione, 2010).

Como membro desta comissão e secretário da Fazenda, Peixoto da Silveira teve um encontro com $\mathrm{JK}$ no qual este pediu um projeto de lei que desse ao Executivo plenos poderes para a construção e mudança da capital. Repassando a tarefa a pessoas mais competentes, Peixoto da Silveira voltou ao Rio de Janeiro para entregar o projeto, que levava uma longa justificação sua, ao líder da bancada goiana, deputado Taciano de Melo. Mais tarde, no entanto, esse projeto de lei foi substituído e aprovado outro, de autoria de Santiago Dantas, pelo qual foi criada a Novacap (Silveira, 1997: 131-133). A partir de então, algumas providências no sentido da concretização da ideia seriam tomadas. No que se refere aos cuidados com a salubridade da região no período da construção de Brasíla, os médicos goianos se destacariam, desempenhando papel importante na interiorização da capital (Vieira, 2007; 2009).

\section{Considerações finais}

Centrando nossa análise sobre as comissões organizadas pelo governo federal nas décadas de 1940 e 1950, buscamos abordar o tema da mudança da capital a partir de um prisma não muito comum na historiografia. A ênfase conferida aos argumentos médicos e geográficos, bem como ao peso que tiveram sobre 
as decisões daqueles diretamente envolvidos com a escolha do melhor local para assento da sede administrativa, teve por objetivo ampliar a compreensão acerca do porquê da definição do Planalto Central como lugar mais adequado para este fim. A solução apresentada pela Comissão Cruls no final do século XIX acabou prevalecendo, mas as justificativas para tanto foram atualizadas ao longo do tempo, embora notemos a recorrência da preocupação com a salubridade local e segurança nacional, esta última incorporada pela geopolítica.

Uma outra questão cara a este trabalho foi a atenção dada à participação goiana no processo de definição da localização e viabilização do projeto mudancista. Tal engajamento ainda é tema pouco explorado pela historiografia, embora seja possível identificar suas origens pelo menos desde o início do século XX (Sá, 2009; Vieira, 2007; 2009; Silva, 1997; Oliveira, 2005a; 2005b). Neste artigo, a participação goiana traduziu-se principalmente pelas ações de Jerônimo Coimbra Bueno e José Peixoto da Silveira, personagens importantes, que souberam lançar mão da posição que ocupavam como membros de comissões para reforçar a propaganda mudancista em prol da causa goiana. Nosso intuito, ao fim e ao cabo, foi considerar de maneira conjugada todos esses aspectos, de modo a reforçar a historicidade do processo que culminou com a inauguração de Brasília, em 21 de abril de 1960.

Notas

1. Alguns destes argumentos já haviam aparecido no opúsculo escrito por Francisco Adolpho de Varnhagen (1877) $A$ questão da capital: marítima ou no interior?, um dos documentos mais citados por aqueles que se ocupam do tema mudancista. No Relatório Cruls, nota-se uma atualização dos mesmos, em um contexto de amplo debate sobre o tema da incorporação dos sertões brasileiros (Lima, 2010).

2. São eles: Odorico Rodrigues de Albuquerque, Arthur Eugênio Magarinos Torres Filho, Antônio Carlos Cardoso, Francisco Xavier Rodrigues de Souza, Jerônimo Coimbra Bueno, Jorge Leal
Burlamaqui, Lucas Lopes, Luiz de Anhaia Mello e Luiz Augusto da Silva Vieira, vicepresidente da comissão.

3. Um dos temas debatidos nas sessões plenárias desta comissão referiu-se à própria ideia de "Planalto Central". Embora ela estivesse associada à região demarcada por Cruls no final do século XIX, os geógrafos envolvidos chegaram a uma conceituação mais ampla do mesmo, o que contribuiu para que outras zonas para além do Retângulo Cruls fossem consideradas (Cf. Pereira, 2010:57-58; Guimarães, 1949a; 1949b). 
4. Referimo-nos como "velhas questões" aos argumentos presentes tanto no trabalho de Varnhagen, já citado neste artigo, como no Relatório Cruls, relacionados à necessidade de interiorização da capital como medida de segurança.

5. Os membros desta comissão eram Álvaro Lobo Leite e Pedro Vasconcelos Barros (do Instituto Oswaldo Cruz), I. da Costa Sobrinho e José Antônio Alves dos Santos (da Faculdade de Higiene de São Paulo) e Celso Caldas (do Departamento Nacional de Saúde).

6. Os outros membros eram Tasso da Cunha Cavalcanti, Paulo Bosiso, Aureliano Luiz de Faria, Jorge d'Escragnolle Taunay, Ademar Barbosa de Almeida Portugal, Flávio Vieira, João Castelo

\section{Referências bibliográficas}

BENEVIDES, Maria Victória. O governo Kubitschek: desenvolvimento econômico e estabilidade política, 1956-1961. Prefácio de Celso Lafer. Rio de Janeiro: Paz e Terra, 1976.

O governo Kubitschek: a esperança como fator de desenvolvimento. In: GOMES, Angela de Castro (org.). O Brasil de $\mathcal{X}$. Rio de Janeiro: Ed. FGV, 2002.

BOJUNGA, Cláudio. $\mathcal{F K}$ : o artista do impossível. Rio de Janeiro: Objetiva, 2001.

BOMENY, Helena. Utopias de cidade: as capitais do modernismo. In: GOMES, Ângela de Castro (org.). O Brasil de $\mathcal{F K}$. Rio de Janeiro: Ed. FGV, 2002

BRASIL. Lei $\mathrm{n}^{\circ} 1803$ de 5 de janeiro de 1953. Autoriza o Poder Executivo a realizar
Branco, Paulo Assis Ribeiro, Valdir Niemeyer, Júlio Américo dos Reis, Jerônimo Coimbra Bueno, Mauro Borges Teixeira e Deoclécio Paulo Antunes.

7. A comissão era composta pelos antigos membros - Aureliano Luiz de Faria, Ademar Barbosa de Almeida Portugal, Flávio Vieira, Paulo Assis Ribeiro, Júlio Américo dos Reis - e mais José Peixoto da Silveira, Silvio Borges de Souza Mota, José Eurico Dias Martins, Fábio Macedo Soares Guimarães, Lucídio Albuquerque, Augusto Sérgio da Silva, Felinto Epitácio Maia e Rubens d'Almeida Horta Porto.

8. Para facilitar os estudos e evitar a especulação imobiliária, as áreas demarcadas foram nomeadas por cores (cf. Castiglione, 2010).

estudos definitivos sobre a localização da Nova Capital da República. < http://www6. senado.gov.br/sicon/PreparaPesquisa.actio n?tipoPesquisa $=3>$. Acesso em 07 de fevereiro de 2007.

A transferência da capital do país para o Planalto Central. Revista Brasileira de Geografia, ano VIII, n. 04, out.-dez., 1946.

A mudança da Capital do País. Revista Brasileira de Geografia, ano X, n. 3-4, jul.-set., 1948a.

Seção especializada de estudos geográficos. In: IBGE. Relatório preliminar apresentado pelo Engenheiro Christovam Leite de Castro, diretor da seção. Anexo n. 1 . Seção Especializada de Estudos Geográficos. Rio de Janeiro: CNG/IBGE, 1948b. 
CASTIGLIONE, Luiz Henrique. Brasília, codinome Vera Cruz: a comissão engenheira que fundou as bases da construção da nova capital. In: SENRA, Nelson (org.). Veredas de Brasília: as expedições geográficas em busca de um sonho. Rio de Janeiro: IBGE, 2010.

CEBALLOS, Viviane G. de. "E a história se fez cidade...": a construção histórica e historiográfica de Brasília. Dissertação (Mestrado em História) - Instituto de Filosofia e Ciências Humanas/Universidade Estadual de Campinas. Campinas, 2005.

COELHO, Djalma P. Justificação da resolução final, escrita pela Presidência da Comissão. In: COMISSÃO DE ESTUDOS PARA A LOCALIZAÇÃO DA NOVA CAPITAL DO BRASIL. Relatório Técnico: contendo a justificação da resolução final tomada pela Comissão, quanto à localização do novo Distrito Federal. Rio de Janeiro, 1948a. Parte 1, v. 1.

. [Justificação de voto]. In: COMISSÃO DE ESTUDOS PARA A LOCALIZAÇÃO DA NOVA CAPITAL DO BRASIL. Relatório Técnico: contendo as justificações e declarações de votos dos membros da Comissão. Rio de Janeiro, 1948b. Parte 1, v. 2.

COMISSÃO DE ESTUDOS PARA A LOCALIZAÇÃO DA NOVA CAPITAL DO BRASIL. Relatório Técnico: contendo a transcrição das atas das reuniões plenárias realizadas pela Comissão. Rio de Janeiro, 1948. Parte 1, v. 3.

COUTO, Ronaldo C. Brasília Kubitschek de Oliveira. Rio de Janeiro: Record, 2001.

CRULS, Luiz. Relatório Cruls: relatório da comissão Exploradora do Planalto Central do Brasil. Brasília: Senado Federal, Conselho Editorial, 2003.

FARO, Clovis de. \& SILVA, Salomão L. Q. da. A década de 1950 e o Programa de Metas. In: GOMES, Ângela de Castro (org.). $O$ Brasil de FK. Rio de Janeiro: Ed. FGV, 2002.
FERREIRA, Luís Otávio. Uma interpretação higienista do Brasil Imperial. In: HEIZER, Alda \& VIDEIRA, Antonio Augusto Passos (orgs.). Ciência, civilização e Império nos trópicos. Rio de Janeiro: Access, 2001.

GOMES, Angela Maria de C. (org.). $O$ Brasil de FK. Rio de Janeiro: Ed. FGV, 2002.

GUIMARÃES, Fábio de M. S. Trabalhos de Campo e de Gabinete da Segunda Expedição Geográfica ao Planalto Central. Revista Brasileira de Geografia, ano XI, n. 04, out-dez, 1949a.

. O Planalto Central e a mudança da capital. Revista Brasileira de Geografia, ano XI, n. 04, out.-dez., 1949b.

KUBITSCHEK, Juscelino. Porque construí Brasília. Brasília: Senado Federal, Conselho Editorial, 2006.

LAFER, Celso. $\mathcal{F K}$ e o Programa de Metas (1956-1961): processo de planejamento e sistema político no Brasil. Rio de Janeiro: Ed. FGV, 2002.

LEOPOLDI, Maria Antonieta P. Crescendo em meio à incerteza: a política econômica do governo JK (1956-1960). In: GOMES, Angela de C. (org.). O Brasil de $\mathcal{F K}$. Rio de Janeiro: Ed. FGV, 2002.

LIMA, Nísia T. Brasília: a capital no sertão. In: SENRA, Nelson (org.). Veredas de Brasília: as expedições geográficas em busca de um sonho. Rio de Janeiro: IBGE, 2010.

LOPES, Lucas. Memórias do desenvolvimento. Rio de Janeiro: Centro da Memória da Eletricidade no Brasil, 1991.

MAIA, João Marcelo Ehlert. As ideias que fazem o Estado andar: imaginação espacial, pensamento brasileiro e território no Brasil Central. Dados, vol.53, n.03, 2010, p. 621-655.

MENDONÇA, Sônia Regina de. Estado e economia no Brasil: opções de desenvolvimento. Rio de Janeiro: Graal, 1985. 
MIYAMOTO, Shiguenoli. Geopolítica e poder no Brasil. Campinas: Papirus, 1995.

MORAES, Antonio Carlos R. Território e História no Brasil. São Paulo: Annablume, 2005.

MOREIRA, Vânia Maria L. Brasília: $a$ construção da nacionalidade - um meio para muitos fins. Vitória: EDUFES, 1998.

OLIVEIRA, Márcio de. A participação goiana na construção de Brasília. Sociedade e Cultura, vol. 8, 2005a, p. 261-271.

A construção simbólica de Brasília: o passado de um mito. Interseções, vol. 7, n. 1, julho de 2005b, p. 73-93.

PEREIRA, Sérgio N. Na boca do sertão ou integrada ao ecúmeno? Militares, estatísticos, geógrafos e a localização da nova capital. In: SENRA (org.). Veredas de Brasília: as expedições geográficas em busca de um sonho. Rio de Janeiro: IBGE, 2010.

RODRIGUES, Jaime. Arquivo "Geraldo Horácio de Paula e Souza”: um acervo sobre história e saúde. Patrimônio e Memória, vol. 04, n. 01, p. 1-15, 2008.

ROSAS, Roberta J. Do paraíso ao grande hospital: dois olhares da ciência sobre o sertão (Goiás - 1892-1912), Dissertação de Mestrado. Brasília: UnB, 1996.

RUELLAN, Francis. Relatório preliminar da primeira expedição geográfica ao Planalto Central. In: IBGE. Relatório preliminar apresentado pelo Engenheiro Christovam Leite de Castro, diretor da Seção. Anexo n. 1. Seção Especializada de Estudos Geográficos. Rio de Janeiro: CNG/ IBGE, 1947.

SÁ, Dominichi M. de. Uma interpretação do Brasil como doença e rotina: a repercussão do relatório médico de Arthur Neiva e Belisário Penna (1917-1935). História, Ciências, Saúde - Manguinhos, Rio de Janeiro, v. 16, supl. 1, jul. 2009, p. 183-203.
SILVA, Luiz Sérgio D. da. $A$ construção de Brasilia: modernidade e periferia. Goiânia: Editora da UFGo, 1997.

SILVEIRA, Peixoto da. A nova capital-por que, para onde e como mudar a capital federal. Rio de Janeiro: Pongetti, 1957.

[s.ed.], Fragmentos do meu tempo. Goiânia:
[9

SKIDMORE, Thomas. Brasil: de Getúlio a Castelo. Rio de Janeiro: Paz e Terra, 1982.

SOUZA, Geraldo H. de. [Justificação de voto]. In: COMISSÃO DE ESTUDOS PARA A LOCALIZAÇÃO DA NOVA CAPITAL DO BRASIL. Relatório Técnico: contendo as justificações e declarações de votos dos membros da Comissão. Rio de Janeiro, 1948. Parte 1, v. 2.

VARNHAGEN, Francisco. A questão da capital: marítima ou no interior? Vienna D’Austria: Imp. do filho de Carlos Gerald edição por conta do autor, 1877.

VERGARA, Moema. Território e saúde: o estudo de Antônio Pimentel sobre o Planalto Central. História, Ciências, Saúde Manguinhos, Rio de Janeiro, v. 15, 2008.

Ciência e história no relatório da Comissão Exploradora do Planalto Central na Primeira República. História, Ciências, Saúde - Manguinhos, Rio de Janeiro, v. 13, n. 4, out.-dez., 2006.

A Comissão Cruls e o projeto de mudança da capital federal na Primeira República. In: SENRA (org.). Veredas de Brasília: as expedições geográficas em busca de um sonho. Rio de Janeiro: IBGE, 2010.

VIEIRA, Luiz da Silva. [Justificação de voto]. In: COMISSÃO DE ESTUDOS PARA A LOCALIZAÇÃO DA NOVA CAPITAL DO BRASIL. Relatório Técnico: contendo as justificações e declarações de votos dos membros da Comissão. Rio de Janeiro, 1948. Parte 1, v. 2. 
VIEIRA, Tamara R. No coração do Brasil, uma capital saudável - a participação dos médicos e sanitaristas na construção de Brasília (1956-1960). História, Ciências, Saúde - Manguinhos, Rio de Janeiro, v. 16, supl. 1, p. 289-312, jul. 2009.

\begin{abstract}
. Uma clareira no sertão? Saúde, nação e região na construção de Brasília (1956-1960). 2007. Dissertação (Mestrado em História das Ciências e da Saúde) - Casa de Oswaldo Cruz/Fiocruz. Rio de Janeiro, 2007.
\end{abstract}

\title{
Resumo
}

O tema da localização da sede do governo federal no Brasil tem motivado estudos que analisam os diferentes marcos temporais da história da transferência da capital para o Planalto Central. Neste artigo, discutimos a importância que argumentos oriundos da medicina e da geopolítica, aliados a interesses regionais, tiveram nas comissões organizadas nas décadas de 1940 e 1950 pelo governo federal, as quais tinham como objetivo escolher o lugar mais adequado para fixação do novo centro político-administrativo do país. Palavras-chave: Brasília; Planalto Central; Goiás; Geografia; Medicina.

\author{
Abstract \\ There are several studies concerning the transfer of federal government seat \\ in Brazil. These studies analyse different timeframes in the history of the \\ location of capital in the Central Plateau. This article will discuss the \\ relevance of medicine and geopolitics arguments, added to regional interests, \\ in the committees organized in the 1940s and 1950s by the federal \\ government that were responsible for choosing the most suitable place for \\ setting the new political and administrative center of the country. \\ Keywords: Brasília; Central Plateau; Goiás; Geography; Medicine.
}

\section{Résumé}

Le sujet du débat autour de l'endroit le plus convenable pour installer le siège du gouvernement fédéral au Brésil motive, il y a quelque temps, des études qui cherchent à analyser les différentes repères temporels de l'histoire du transfert de la capitale au Plateau central. Dans cet article, nous examinons l'importance du rôle que des arguments provenus de la médecine ainsi que de la géopolitique, alliés à des intérêts régionaux, eurent à l'intérieur des comissions constituées pendant les années 40 et 50 du XXe siècle par le gouvernement fédéral, lesquelles avaient pour but de choisir l'endroit le plus adéquat pour le nouveau centre politico-administratif du pays. Mots-clés: Brasília; Plateau Central; Goiás; Géographie; Médecine. 